\title{
Laboratory testing of a shuttle car canopy air curtain for respirable coal mine dust control
}

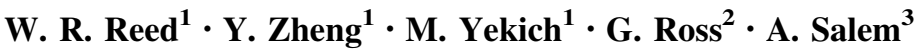

Received: 11 May 2018/Revised: 11 June 2018/Accepted: 6 September 2018/Published online: 17 September 2018

(C) The Author(s) 2018

\begin{abstract}
Canopy air curtain (CAC) technology has been developed by the National Institute for Occupational Safety and Health (NIOSH) for use on continuous miners and subsequently roof bolting machines in underground coal mines to protect operators of these machines from overexposure to respirable coal mine dust. The next logical progression is to develop a CAC for shuttle cars to protect operators from the same overexposures. NIOSH awarded a contract to Marshall University and J.H. Fletcher to develop the shuttle car CAC. NIOSH conducted laboratory testing to determine the dust control efficiency of the shuttle car CAC. Testing was conducted on two different cab configurations: a center drive similar to that on a Joy 10SC32AA cab model and an end drive similar to that on a Joy 10SC32AB cab model. Three different ventilation velocities were tested-0.61, 2.0, $4.3 \mathrm{~m} / \mathrm{s}(120,400$, and $850 \mathrm{fpm})$. The lowest, $0.61 \mathrm{~m} / \mathrm{s}(120 \mathrm{fpm})$, represented the ventilation velocity encountered during loading by the continuous miner, while the $4.3 \mathrm{~m} / \mathrm{s}(850 \mathrm{fpm})$ velocity represented ventilation velocity airflow over the shuttle car while tramming against ventilation airflow. Test results showed an average of the dust control efficiencies ranging from 74 to $83 \%$ for $0.61 \mathrm{~m} / \mathrm{s}(120 \mathrm{fpm}), 39 \%-43 \%$ for $2.0 \mathrm{~m} / \mathrm{s}(400$ $\mathrm{fpm})$, and $6 \%-16 \%$ for $4.3 \mathrm{~m} / \mathrm{s}(850 \mathrm{fpm})$. Incorporating an airflow spoiler to the shuttle car CAC design and placing the CAC so that it is located $22.86 \mathrm{~cm}$ (9 in.) forward of the operator improved the dust control efficiency to $51 \%-55 \%$ for $4.3 \mathrm{~m} / \mathrm{s}(850 \mathrm{fpm})$ with minimal impact on dust control efficiencies for lower ventilation velocities. These laboratory tests demonstrate that the newly developed shuttle car CAC has the potential to successfully protect shuttle car operators from coal mine respirable dust overexposures.
\end{abstract}

Keywords Shuttle car · Canopy air curtain · Dust · Airflow · Coal mining

The findings and conclusions in this report are those of the author(s) and do not necessarily represent of the official position of the National Institute for Occupational Safety and Health. Mention of any company name, product, or software does not constitute endorsement by NIOSH.

W. R. Reed

rreed@cdc.gov

1 Pittsburgh Mining Research Division, Centers for Disease Control and Prevention, National Institute for Occupational Safety and Health, 626 Cochrans Mill Rd., Pittsburgh, PA 15236, USA

2 J.H. Fletcher, Inc., Huntington, WV, USA

3 Marshall University, Huntington, WV, USA

\section{Introduction}

The development of the canopy air curtain (CAC) dates back to the 1970s starting with the initial development of the CAC by the Donaldson Company, Inc. under contract from the U.S. Bureau of Mines (Krisko 1975). This CAC was originally developed for continuous miner operators when continuous mining machines had cabs. The need for a $\mathrm{CAC}$ on the continuous miner was eliminated when the cab was removed from the machine design. However, CAC development progressed to include CAC designs for a roof bolting machine to protect roof bolters from respirable coal mine dust (Goodman and Organiscak 2002; Listak and Beck 2012; Reed et al. 2017). This roof bolting machine CAC research continues to the present day. 
National Institute for Occupational Safety and Health (NIOSH) conducted a study which indicated that coal mine respirable dust overexposures are a concern for shuttle car operators when blowing face ventilation is used to ventilate the continuous miner face while cutting and loading coal. Table 1 summarizes the averages of the coal mine respirable dust exposure of shuttle car operators measured during continuous miner operation-cutting and loading coal-at different mining operations (Potts et al. 2011). In Table 1, straight cuts are defined as the continuous miner cutting straight into the entry. Right and left cuts are defined as the continuous miner cutting or turning a crosscut in the respective direction off the entry.

These exposures occur while the shuttle car operator is operating downwind of the continuous miner, waiting to be loaded with coal. It can be seen, from Table 1, that many of the exposures exceed $1.5 \mathrm{mg} / \mathrm{m}^{3}$. While these exposures only occur during continuous miner cutting and loading cycles when the shuttle car is downwind of the miner, it can be seen that they may be high enough to result in overexposures.

Research on the CAC is being expanded to include a CAC for shuttle car operators to provide respiratory protection from respirable coal mine dust. Ambient mine air is filtered and blown over the operator through a plenum built into the shuttle car canopy. A new version of the CAC, specifically designed for the shuttle car, has been developed under a NIOSH contract by Marshall University and J.H. Fletcher [contract \#200-2015-63485], and is based upon NIOSH design recommendations. NIOSH completed the required laboratory testing of the shuttle car CAC to determine its ability to reduce the shuttle car operators' respirable coal dust exposure. This paper details results of testing the shuttle car CAC in $0.61 \mathrm{~m} / \mathrm{s}(120 \mathrm{fpm}), 2.0 \mathrm{~m} / \mathrm{s}$ (400 fpm), and $4.3 \mathrm{~m} / \mathrm{s}(850 \mathrm{fpm})$ ventilation airflows. Since results with $4.3 \mathrm{~m} / \mathrm{s}(850 \mathrm{fpm})$ ventilation airflows were not satisfactory additional tests with modifications to the location and design of the CAC were conducted. Modifications included moving the CAC $22.86 \mathrm{~cm}$ (9 in.) forward of operator location and adding a $5.08 \mathrm{~cm} \mathrm{(2} \mathrm{in.)}$ spoiler. These modifications provided satisfactory results, thus showing that a shuttle car CAC can be a viable dust control device for the protection of shuttle car operators to coal mine respirable dust.

\subsection{Testing}

The testing of the shuttle car CAC was conducted on a simulated shuttle car cab in an airflow corridor at NIOSH Pittsburgh Mining Research Division (PMRD) to determine effectiveness for dust reduction. The corridor dimensions were $2.29 \mathrm{~m}$ (90 in.) high by $1.98 \mathrm{~m}$ (78 in.) wide by an $18.9 \mathrm{~m}$ (62 ft.) long corridor. Two different shuttle car cab designs were evaluated-a center drive cab similar to that on a Joy 10SC32AA model shuttle car and an end-drive cab similar to that on a Joy 10SC $32 \mathrm{AB}$ shuttle car. These two shuttle car models were found to be the most commonly used in underground coal mines. These designs are shown in Figs. 1 and 2. The dimensions are approximated from actual measurements of typical shuttle cars at an operating underground coal mine site. During setup, the cabs were placed in the center of NIOSH's longwall gallery return airway at $25.4-30.5 \mathrm{~cm}(10-12 \mathrm{in}$.) above the floor as specified by the ground clearance for each shuttle car model. No obstructions to cab openings, such as wheel fenders, caging of cab openings, etc. were simulated.

The CAC (Fig. 3) was attached onto the bottom side of the shuttle car roof (canopy) and centered over the seating area of the operator. For purposes of lab testing, all necessary components for generating airflow, including the blower, drive, and intake filter were set up outside the test area. Figure 4 shows the center-drive cab setup for testing.

Table 1 Average coal mine respirable dust concentrations with $85 \%$ confidence intervals, measured at the location of shuttle car operators when the continuous miner cuts and loads cars (Potts et al. 2011)

\begin{tabular}{|c|c|c|c|c|c|c|c|c|c|c|}
\hline Mine & Cut depth (m) & Straight cut $\left(\mathrm{mg} / \mathrm{m}^{3}\right)$ & & $85 \% \mathrm{CI}$ & Right cut $\left(\mathrm{mg} / \mathrm{m}^{3}\right)$ & & $85 \% \mathrm{CI}$ & Left cut $\left(\mathrm{mg} / \mathrm{m}^{3}\right)$ & & $85 \% \mathrm{CI}$ \\
\hline \multirow[t]{2}{*}{$\mathrm{A}$} & 6.1 & 4.13 & \pm & 0.70 & 5.31 & \pm & 1.01 & NA & & NA \\
\hline & 12.2 & 6.39 & \pm & 1.50 & 3.55 & \pm & 0.58 & NA & & NA \\
\hline \multirow[t]{2}{*}{$\mathrm{D}$} & 6.1 & 0.75 & \pm & 0.36 & NA & & NA & NA & & NA \\
\hline & 9.2 & 2.73 & \pm & 0.68 & NA & & NA & NA & & NA \\
\hline \multirow[t]{2}{*}{$\mathrm{E}$} & 6.1 & 1.27 & \pm & 0.18 & 1.24 & \pm & 0.25 & 1.50 & \pm & 0.35 \\
\hline & 12.2 & 1.15 & \pm & 0.23 & 1.13 & \pm & 0.29 & 1.10 & \pm & 0.45 \\
\hline \multirow[t]{2}{*}{$\mathrm{F}$} & 6.1 & 1.77 & \pm & 0.24 & NA & & NA & NA & & NA \\
\hline & 9.2 & 2.13 & \pm & 0.25 & NA & & NA & NA & & NA \\
\hline
\end{tabular}

CI confidence interval, NA not available 


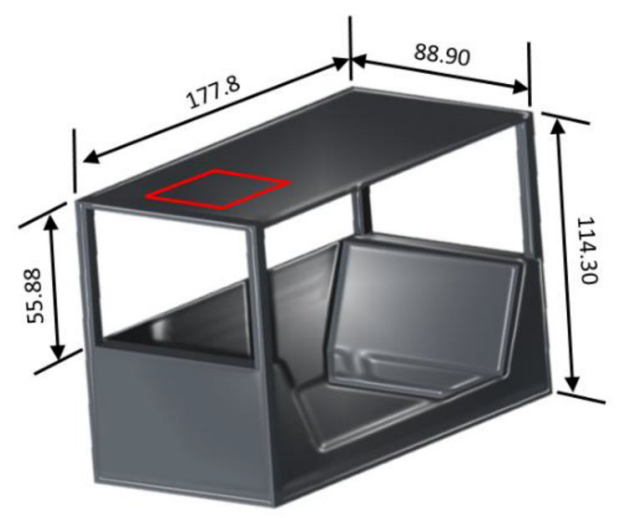

Fig. 1 The center-drive shuttle car cab for the Joy 10SC32AA (dimensions in centimeters). The red outline shows the location of the canopy air curtain underneath the cab roof during testing (drawing by $\mathrm{NIOSH})$

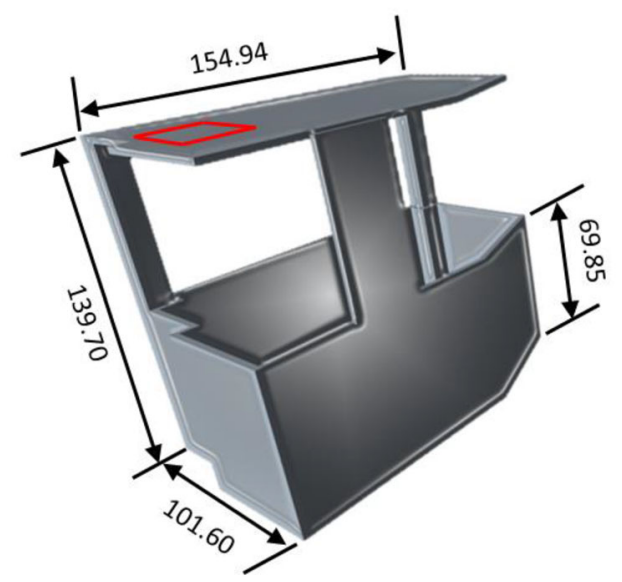

Fig. 2 The end-drive shuttle car cab for the Joy 10SC $32 \mathrm{AB}$ (dimensions in centimeters). The red outline shows the location of the canopy air curtain underneath the cab roof during testing (drawing by $\mathrm{NIOSH})$

\subsection{Sampling method}

Both gravimetric and instantaneous samplers were used for testing the CAC for respirable dust control. Each gravimetric sampler consisted of an Escort ELF $^{\circledR}$ pump, a 10-mm Dorr-Oliver cyclone, and a 37-mm, 5- $\mu \mathrm{m}$ PVC filter. The Escort ELF pumps were calibrated to maintain $2.0 \mathrm{~L} / \mathrm{min}$ airflow. The Thermo Scientific pDR-1000 ${ }^{\circledR}$ was used as the instantaneous sampler. The typical sampling package was comprised of two gravimetric samplers and one instantaneous sampler. One sampling package was

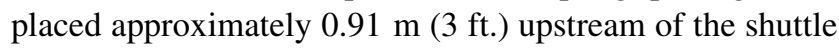
car cab and another was placed $0.91 \mathrm{~m}$ (3 ft.) downstream of the shuttle car cab. These sampling packages monitored the respirable upstream and downstream dust concentrations to ensure consistent dust concentrations throughout the test.

To test the CAC for dust control effectiveness, the sampling heads of four gravimetric samplers were placed at different locations at approximately $25.4 \mathrm{~cm}$ (10 in.) underneath the CAC (Fig. 5). A pDR-1000 was also placed in the center of the four gravimetric samplers underneath the CAC (Fig. 6). Later on during testing of the modifications to the CAC, continuous personal dust monitors (CPDM) Thermo Fisher Scientific Model 3600 were used in place of the gravimetric samplers due ease of obtaining immediate results.

The amount of air supply to the canopy was measured using a hot wire anemometer. Blower velocity measurements were conducted by inserting the anemometer at a port in a $1.52-\mathrm{m}(5-\mathrm{ft})$ length of straight $10.2-\mathrm{cm}$ (4-in.) PVC pipe connected to the blower outlet. The port was located approximately $1 \mathrm{~m}$ (40 in.) from the blower outlet to minimize turbulent airflow effects from the blower outlet.

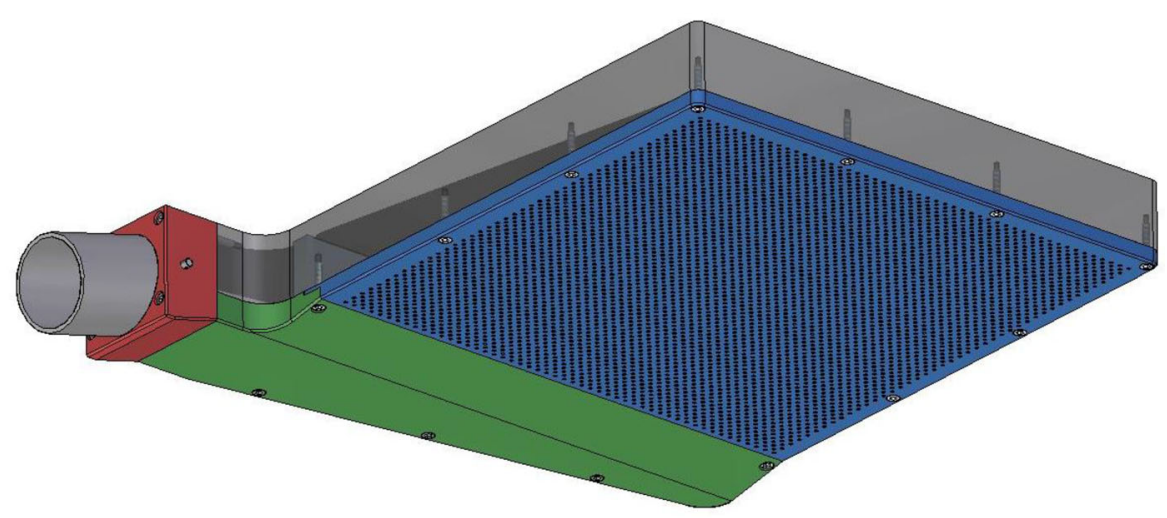

Fig. 3 The canopy air curtain underneath the roof of the shuttle car (drawing by Marshall University and J.H. Fletcher, Inc.) 


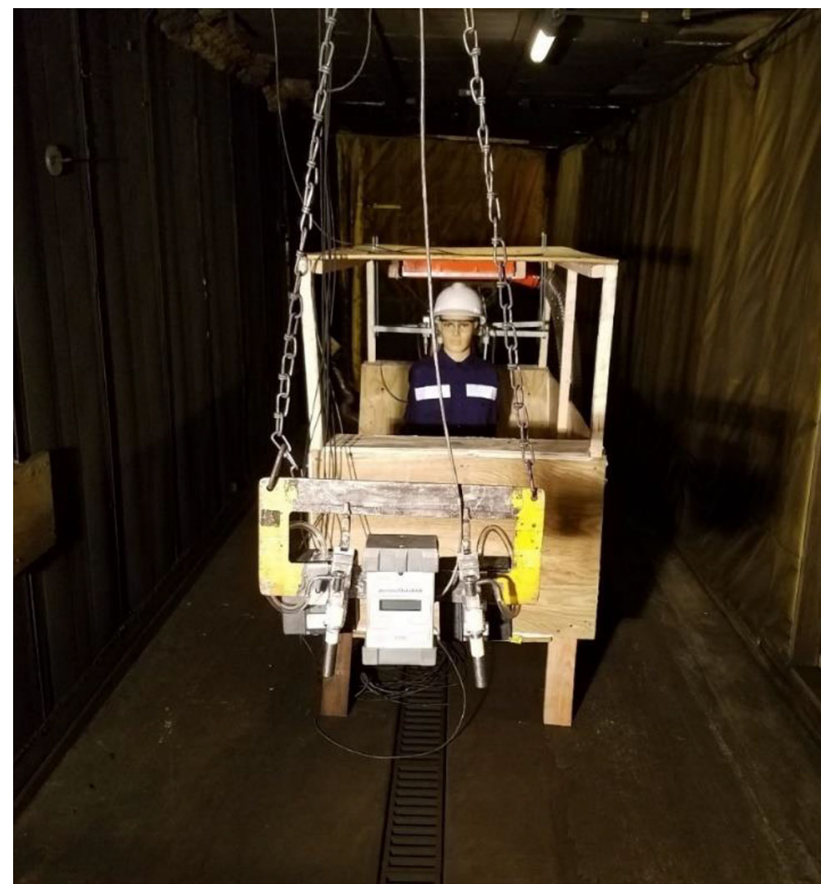

Fig. 4 Photo showing the setup of the center-drive cab for testing with the manikin used for centering the CAC over the shuttle car operator

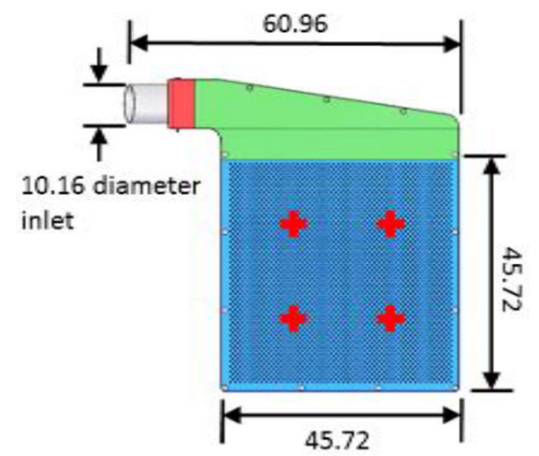

Gravimetric sampling locations

Fig. 5 The canopy air curtain showing gravimetric filter locations (measurements on figure are in centimeters)

\subsection{Test procedure}

Three ventilation air velocities of $4.3 \mathrm{~m} / \mathrm{s}(850 \mathrm{fpm})$, $2.0 \mathrm{~m} / \mathrm{s}(400 \mathrm{fpm})$, and $0.61 \mathrm{~m} / \mathrm{s}(120 \mathrm{fpm})$ were tested in the return section where the CAC test stand was located. The $0.61 \mathrm{~m} / \mathrm{s}(120 \mathrm{fpm})$ represented the air velocity encountered when being loaded by the continuous miner, and the $4.3 \mathrm{~m} / \mathrm{s}(850 \mathrm{fpm})$ represented the max air velocity encountered when tramming to the feeder. The $2.0 \mathrm{~m} / \mathrm{s}$ (400 fpm) ventilation air velocity was tested as an approximate midway point between the other two ventilation velocities. A dust feeder was used to obtain an upwind

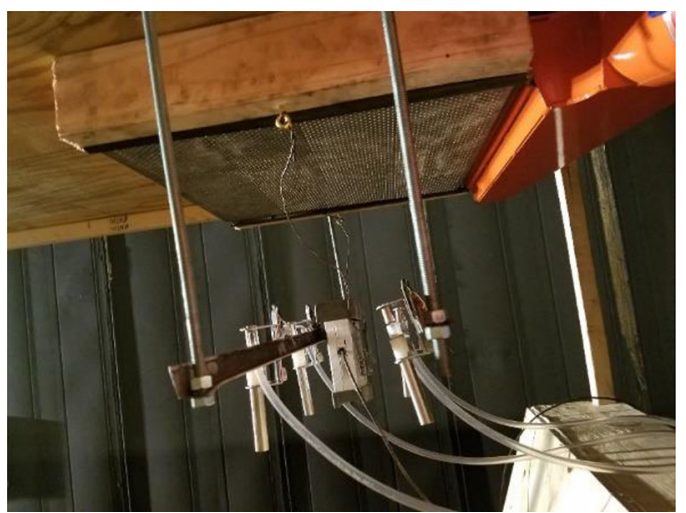

Fig. 6 Photo showing the sampling locations, both the pDR-1000 and 4 gravimetric samplers, underneath the $\mathrm{CAC}$

respirable dust concentration targeting approximately $6.0 \mathrm{mg} / \mathrm{m}^{3}$. This concentration was selected because previous NIOSH studies have shown that this level of dust is encountered in the return of continuous miners using scrubbers (Colinet et al. 2013). The instantaneous sampler was used to monitor dust concentrations during testing.

Once the $6.0 \mathrm{mg} / \mathrm{m}^{3}$ concentration was achieved, the CAC blower was turned on to supply airflow to the plenum underneath the cab roof. Sampling was then started and tests were conducted for $30 \mathrm{~min}$. Initially, three trials for each test were conducted, resulting in a total of nine tests for each cab type - three tests at $0.61 \mathrm{~m} / \mathrm{s}(120 \mathrm{fpm})$, three tests at $2.0 \mathrm{~m} / \mathrm{s}(400 \mathrm{fpm})$, and three tests at $4.3 \mathrm{~m} / \mathrm{s}(850$ $\mathrm{fpm})$. The data was analyzed using the estimation of the mean of a population using a single sample (Natrella 1963) to determine the need for additional trials, which were added as needed.

The effectiveness of the CAC was determined by comparing the respirable dust concentrations from the four gravimetric filters underneath the $\mathrm{CAC}$ with the respirable dust concentrations from the two gravimetric filters upstream from the test stand. The following equation was used for calculating the respirable dust control:

$\%$ reduction $=\left[1-\left(\frac{\text { Average canopy gravs }}{\text { Average upstream gravs }}\right)\right] \times 100 \%$

where $\%$ reduction $=$ respirable dust reduction in percentage. Average canopy gravs $=$ average of the dust concentrations $\left(\mathrm{mg} / \mathrm{m}^{3}\right)$ from the four gravimetric filters underneath the canopy. Average upstream gravs $=$ average of the dust concentrations $\left(\mathrm{mg} / \mathrm{m}^{3}\right)$ from the two gravimetric filters upstream of the test canopy.

During all testing, the blower velocity measurements taken in the $10.16 \mathrm{~cm}$ (4 in.) PVC pipe varied from 17.45 to $25.53 \mathrm{~m} / \mathrm{s}$ (3436-5025 fpm). These measurements were only taken before and after the trial was completed. The 
average of the before and after measurements was used to calculate the velocity during the trial. Converting the velocities to air quantities showed that the blower provided anywhere from 0.14 to $0.21 \mathrm{~m}^{3} / \mathrm{s}(299-439 \mathrm{cfm})$ to the CAC. Correlation coefficients were calculated comparing the airflow quantities to the dust reductions. The results of the correlation calculations, -0.38 for end drive cars and 0.53 for center drive cars, never showed a strong correlation (correlation coefficients $>10.75 \mathrm{I}$ ) of airflow quantity provided by the blower to dust reductions provided by the plenum. The dry temperature ranged from 16.7 to $23.9{ }^{\circ} \mathrm{C}$ $\left(62-75^{\circ} \mathrm{F}\right)$, with the relative humidity ranging from 23.4 to $67.4 \%$. The barometric pressure ranged from 991 to 1029 mbar.

\subsection{Results}

In each case, for both center-drive and end-drive cabs, the column labeled "Count" represents the number of trials tested. Initially, three trials were tested. Additional trials were added based upon the equation (Natrella 1963):

$n=\frac{\sigma^{2} z_{\alpha=0.05}^{2}}{d^{2}}$

where $n=$ sample size required [number of trials required], $\sigma=$ standard deviation of number of trials, $z_{\alpha=0.05}=$ standard normal distribution value $=1.64$ at $90 \%{ }^{1}$ confidence for two-tailed test, $d=$ allowable error.

In reviewing all trials, the number of trials performed was sufficient with the allowable error for the resulting dust reductions set at $\pm 5 \%$.

The dust control results from the testing are shown in Tables 2 and 3 along with associated statistics, such as standard deviation and upper and lower 95\% confidence intervals. It can be seen that the canopy air curtain on the center-drive cab has a dust control efficiency of approximately $74 \%$ in $0.61 \mathrm{~m} / \mathrm{s}(120 \mathrm{fpm})$ ventilation airflow. In $4.3 \mathrm{~m} / \mathrm{s}(850 \mathrm{fpm})$ ventilation airflow, the dust reduction was very low at $16 \%$, demonstrating that the dust control efficiency in high airflow velocities was reduced.

For the end-drive cab, it can be seen that the canopy air curtain has a dust control efficiency of up to approximately $83 \%$ in $0.61 \mathrm{~m} / \mathrm{g}(120 \mathrm{fpm})$ ventilation airflow. In $4.3 \mathrm{~m} / \mathrm{s}$ (850 fpm) ventilation airflow, the dust reduction was reduced to $6 \%$, demonstrating that its dust control

\footnotetext{
1 The confidence level was relaxed to $90 \%$ from the commonly used $95 \%$ level for this lab testing. While lab testing has much better control over influences on testing, there are still factors which cannot be controlled such as air properties, dust feed moisture content, airflow fluctuations, dust feed variations, etc. Additionally, laboratory availability can place time constraints limits on lab testing limiting the number of trials completed. A $90 \%$ confidence level is still a robust standard.
}

efficiency in high airflow velocities will also be reduced for end-drive cabs.

Past research has shown that as the ventilation velocity increases, the dust control efficiency of the CAC decreases (Engel et al. 1987). The results of this testing proved no different. However, the contract requires the ability to reduce the shuttle car operator's respirable coal dust exposure by at least $60 \%$ and poor performance during tramming-where relative velocities are highest-could result in efficiencies below this level.

\subsection{Improvement of canopy air curtain dust control efficiencies}

Because the contract focuses on shuttle cars with centerdrive cabs, subsequent testing to improve the dust control efficiency was completed on the canopy air curtain installed on center-drive cabs. During this testing personal dust monitors (PDM) were used. The PDM allows downloading of the dust concentration data, which provides for quicker turnaround of results compared to weighing gravimetric filters. Therefore, PDMs were used in place of all gravimetric samplers, while the pDRs were still used to provide instantaneous dust concentration readings for monitoring dust inside the test facility.

Reviewing the previous reports on canopy air curtain development from Marshall University/J.H. Fletcher \& Co., Inc., the cross-sections resulting from computational fluid dynamic (CFD) simulations were studied for potential improvements. Of interest were the CFD model results of the canopy air curtain with approximately $4.2 \mathrm{~m} / \mathrm{s}$ (830 fpm) lateral ventilation flow (Salem et al. 2016). Figure 7 presents the results of the CFD analysis showing results in side, plan, and isometric views. The CAC plenum is centrally located atop the CFD modeled volume and is outlined in red. The airstream lines (blue to light green color) are shown emanating from the plenum with the streamflow immediately pushed downstream due to the high $4.2 \mathrm{~m} / \mathrm{s}$ (830 cfm) ventilation flow. Normally, airstream flow from the plenum in low velocity ventilation air emanates straight from the plenum with no deflection. The alignment of these airstream lines due to the deflection caused by the high $4.2 \mathrm{~m} / \mathrm{s}(830 \mathrm{cfm})$ ventilation airflow demonstrates that the airflow protection the canopy offers to the worker seems to shift downwind in high-velocity ventilation airflows. From the observation of the different views displayed in this figure, generated by CFD, the canopy air curtain was shifted approximately $22.86 \mathrm{~cm}$ (9 in.) forward of the shuttle car operator's position, and a front spoiler was added in an attempt to redirect ventilation airflow to improve its performance for dust control.

The front spoiler, consisting of a $12.7-15.2 \mathrm{~cm}$ (5-6 in.) wide piece of plywood that extended across the entire 
Table 2 Dust control reduction and associated statistics for center-drive shuttle car cabs at different ventilation airflows

\begin{tabular}{lllllll}
\hline Description & Vent airflow $(\mathrm{m} / \mathrm{s})$ & Average reduction $(\%)$ & Standard deviation & Count & Upper CI (95\%) & Lower CI (95\%) \\
\hline Center drive & 0.61 & 73.7 & 3.1 & 5 & 76.4 & 71.0 \\
Center drive & 2.03 & 42.6 & 2.7 & 3 & 45.6 & 39.6 \\
Center drive & 4.32 & 16.3 & 1.5 & 5 & 17.6 & 15.0 \\
\hline
\end{tabular}

CI confidence interval

width of the center-drive cab, was added to the roof of the cab. Additionally, it was oriented at $64^{\circ}$ from the horizontal and extended approximately $5.08 \mathrm{~cm}$ ( 2 in.) below the canopy plenum outlets as shown in Fig. 8. The first series of tests placed the canopy centrally in the cab underneath the cab roof with a front spoiler. The sampling locations were not moved with the CAC and were located over the operator position. However, for this first series of tests, two additional samplers were added in front of the existing sampling rows to include sample locations $25.4 \mathrm{~cm}$ (10 in.) directly underneath the CAC (Fig. 10).
The second series of tests used the same spoiler, but moved the canopy air curtain from the centered position to a location $22.9 \mathrm{~cm}$ (9 in.) forward from the original overoperator position (Fig. 9). Again, the sampling locations were not moved with the CAC. They were left in place, centered over the operator position. However, for this second series of tests, one additional row of samplers was added to include sample locations $25.4 \mathrm{~cm} \mathrm{(10} \mathrm{in.)}$ underneath the CAC (Fig. 10). During testing two CPDM per row were used, totaling six CPDMs, replacing the gravimetric samplers. In all subsequent analysis for CAC

Table 3 Dust control reduction and associated statistics for end-drive shuttle car cabs at different ventilation airflows

\begin{tabular}{lllllll}
\hline Description & Vent airflow $(\mathrm{m} / \mathrm{s})$ & Average reduction $(\%)$ & Standard deviation & Count & Upper CI (95\%) & Lower CI (95\%) \\
\hline End drive & 0.61 & 82.8 & 1.4 & 5 & 84.0 & 81.5 \\
End drive & 2.03 & 38.6 & 6.5 & 5 & 44.3 & 32.8 \\
End drive & 4.32 & 6.2 & 3.4 & 6 & 8.9 & 3.5 \\
\hline
\end{tabular}

CI confidence interval

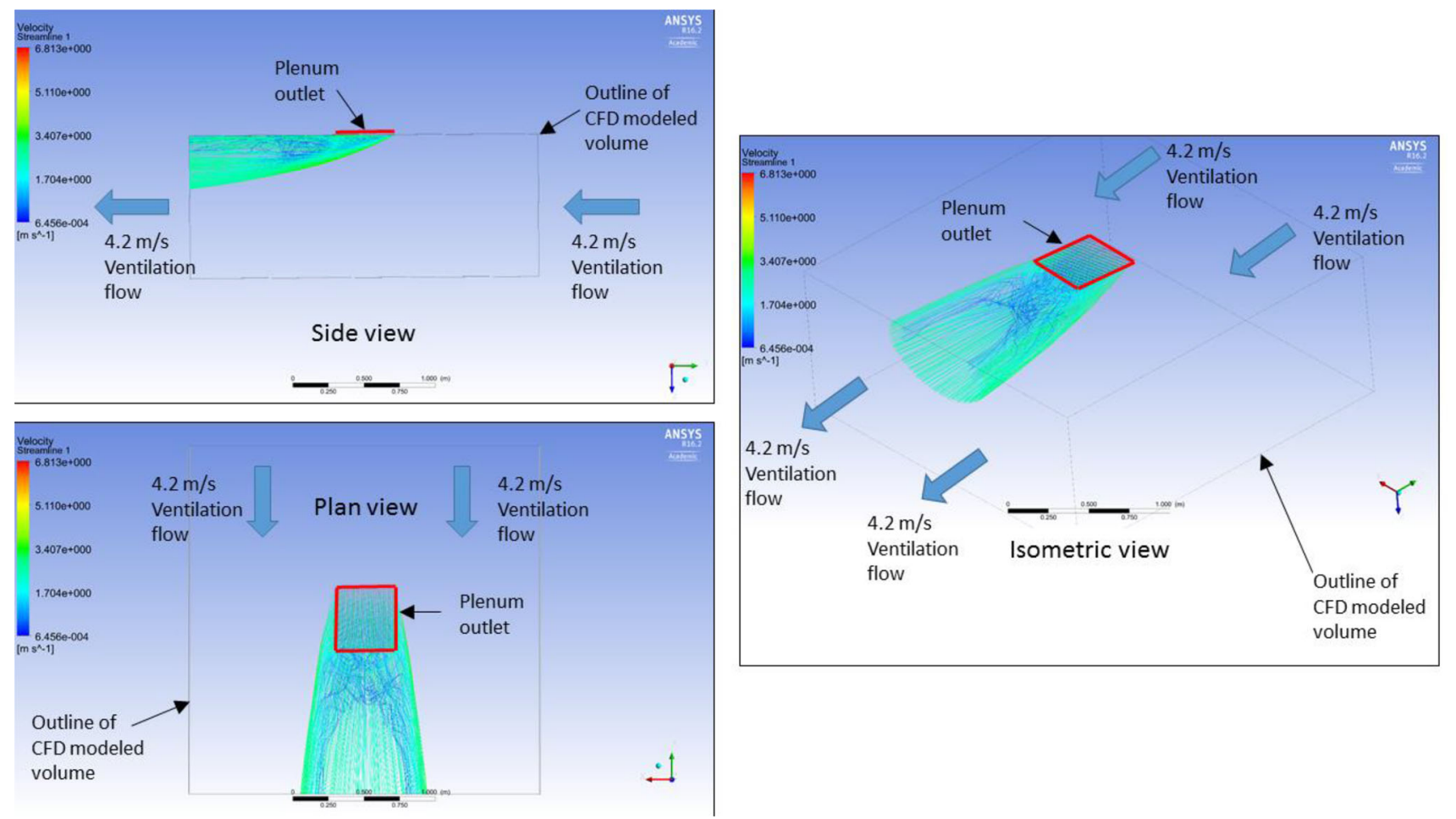

Fig. 7 CFD simulation results showing airflow streams from shuttle car CAC plenum in $4.2 \mathrm{~m} / \mathrm{s}$ ventilation airflow (Marshall University) 


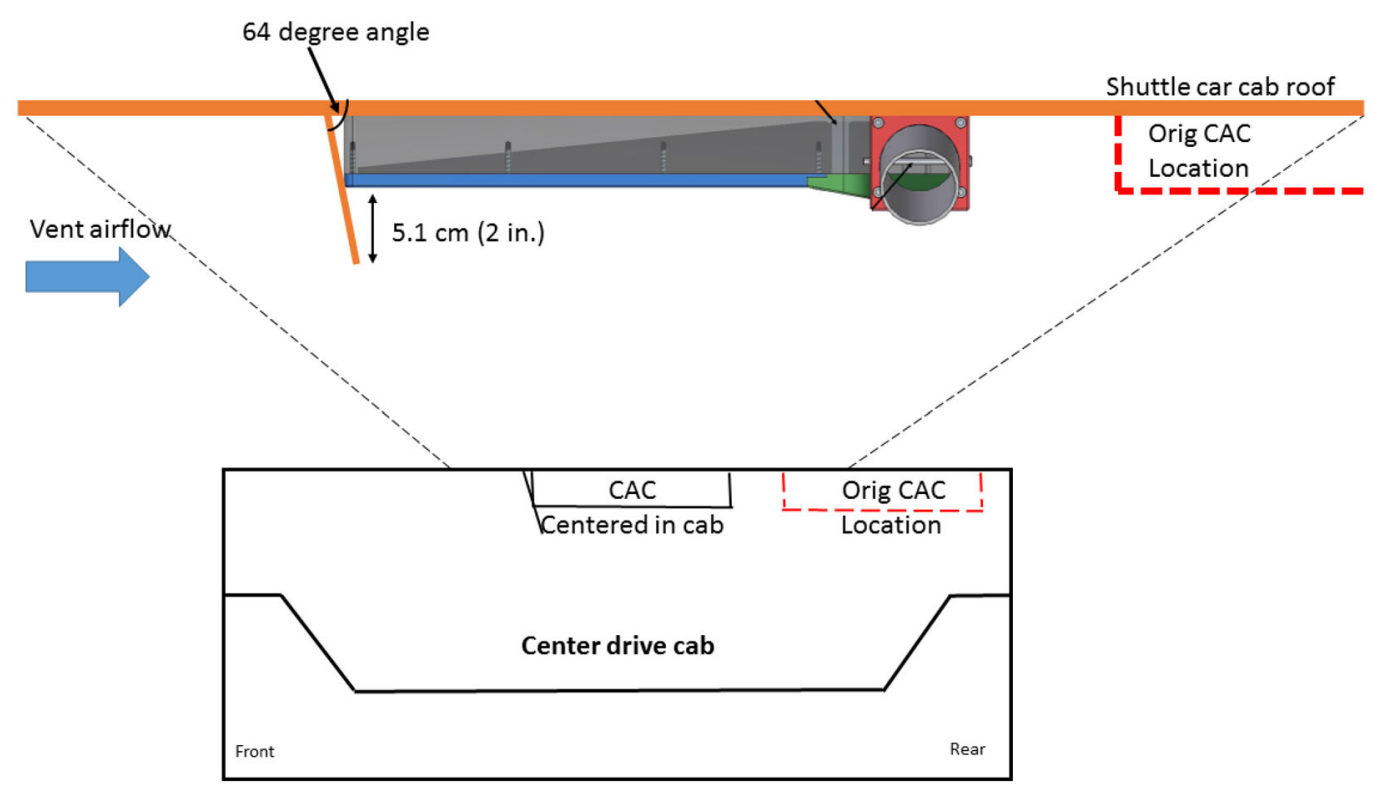

Fig. 8 Canopy air curtain underneath cab roof displaying spoiler to redirect ventilation airflow

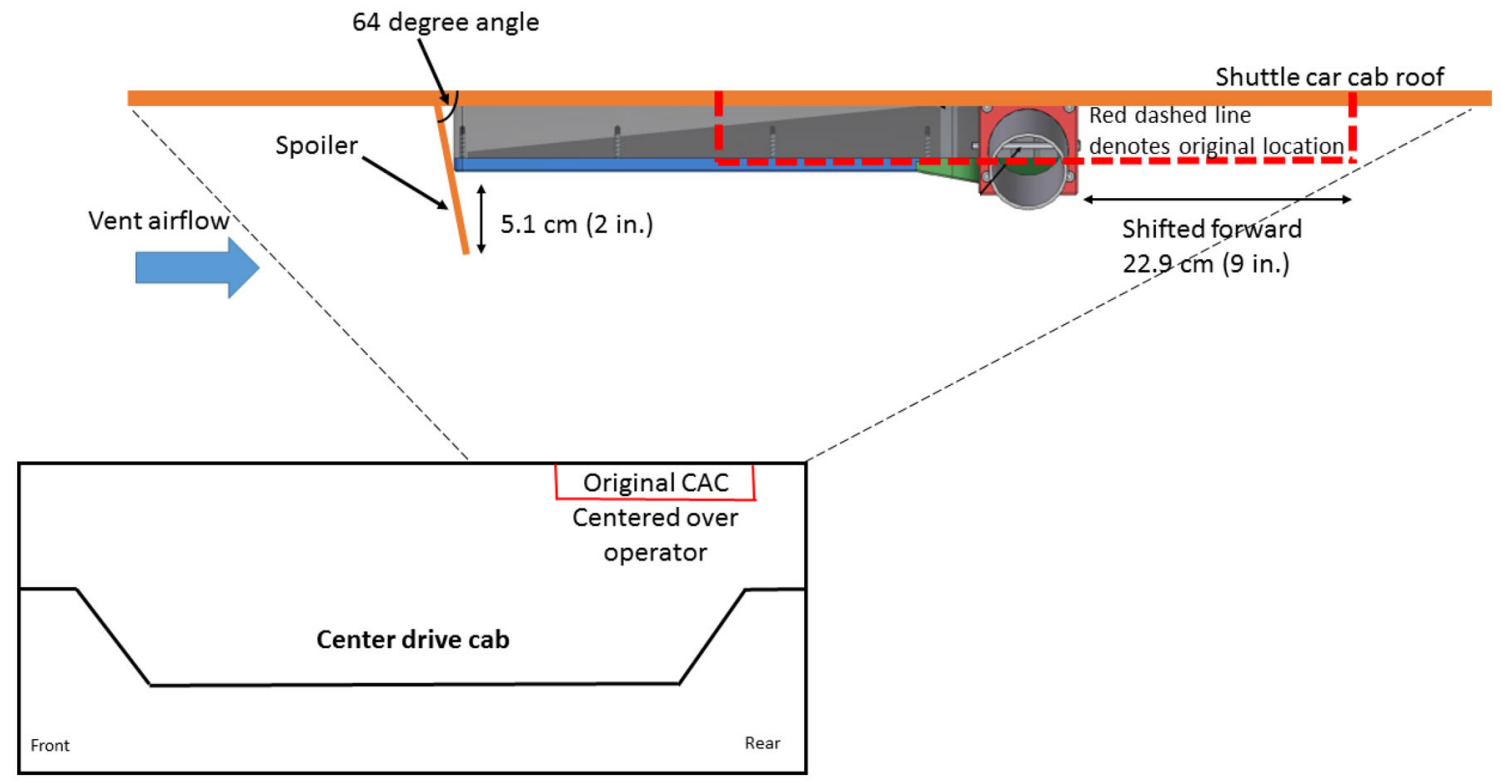

Fig. 9 Canopy air curtain underneath cab roof, displaying forward shift of canopy location $22.9 \mathrm{~cm}(9$ in.) and spoiler to redirect ventilation airflow

respirable dust reductions, Average Canopy Gravs from Eq. (1) averaged the results of all six samplers underneath the CAC area of influence. Results of these tests can be seen in Table 4.

The canopy centered underneath the cab increased the average dust reduction to $36 \%$ (from 16\%). Reviewing the CFD analysis of the CAC showed that moving the CAC only $22.86 \mathrm{~cm}(9 \mathrm{in}$.) forward might provide better results. Therefore, tests that centered the CAC underneath the cab were discontinued and tests that moved the CAC $22.86 \mathrm{~cm}$
(9 in.) forward were tested. Test results showed that the combination of the spoiler and moving the CAC $22.86 \mathrm{~cm}$ (9 in.) forward of the operator seemed to allow the CAC to perform better in the high ventilation airflows, having a $51 \%$ average reduction in $4.3 \mathrm{~m} / \mathrm{s}(850 \mathrm{fpm})$. The CAC also performed better with $66 \%$ dust reduction at $2.0 \mathrm{~m} / \mathrm{s}$ (400 fpm) ventilation airflow. At $0.61 \mathrm{~m} / \mathrm{s}(120 \mathrm{fpm})$, the respirable dust reduction was $70 \%$. The $51 \%$ dust reduction at $4.3 \mathrm{~m} / \mathrm{s}(850 \mathrm{fpm})$ is a substantial increase in dust reduction from the canopy without any modifications to the 


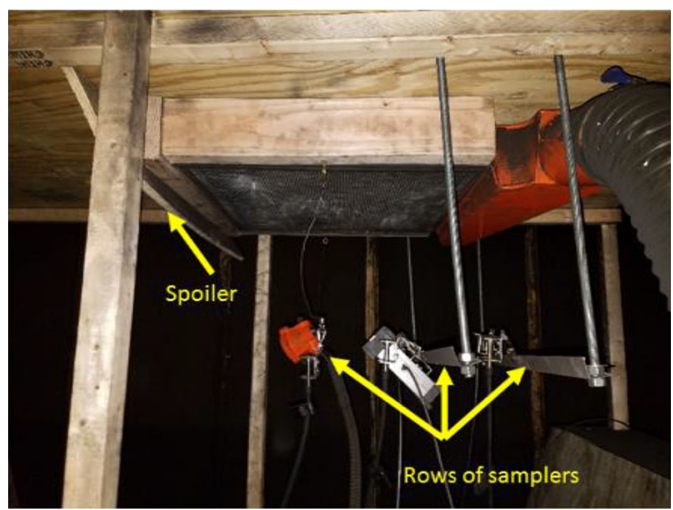

Fig. 10 Photo showing additional sampling row added to provide full sampling coverage underneath the CAC. Spoiler is shown on the front of the $\mathrm{CAC}$

CAC itself. In reviewing all results, the number of samples was sufficient when setting the allowable error at $\pm 5 \%$ in dust reduction. It is assumed that these results will translate to equivalent results for the end-drive cabs.
A single test with the CAC moved $22.86 \mathrm{~cm}$ (9 in.) forward with a spoiler and an additional dummy CAC installed in front, which represented the planned design of two CACs installed underneath the cab roof, showed that the dust reduction dropped to $35 \%$ at $4.3 \mathrm{~m} / \mathrm{s}(850 \mathrm{fpm})$, similar to the results in Table 4 with the CAC centered underneath the cab roof. Additional testing, which simulated the two canopies flush mounted onto the roof with one spoiler with a $10.16 \mathrm{~cm}$ (4-in.) drop instead of a $5.08 \mathrm{~cm}$ (2 in.) drop (Fig. 11), showed better results [a 55\% reduction at $4.3 \mathrm{~m} / \mathrm{s}(850 \mathrm{fpm})]$.

The results in Table 5 show that the canopies flush mounted onto the shuttle car roof will have better success in reducing respirable dust for the shuttle car operator; similar results, as shown in Table 4, were provided by the CAC with the spoiler moved 22.86 (9 in.) forward.

Table 4 Dust control reduction and associated statistics for a center-drive shuttle car at different ventilation airflows with different canopy configurations as shown in Figs. 8 and 9

\begin{tabular}{|c|c|c|c|c|c|c|}
\hline Description & $\begin{array}{l}\text { Vent airflow } \\
(\mathrm{m} / \mathrm{s})\end{array}$ & $\begin{array}{l}\text { Average } \\
\text { reduction }(\%)\end{array}$ & $\begin{array}{l}\text { Standard } \\
\text { deviation }\end{array}$ & Count & $\begin{array}{l}\text { Upper CI } \\
(95 \%)\end{array}$ & $\begin{array}{l}\text { Lower CI } \\
(95 \%)\end{array}$ \\
\hline Canopy with spoiler, canopy centered underneath cab & 4.32 & 36.2 & 0.43 & 3 & 36.7 & 35.7 \\
\hline $\begin{array}{l}\text { Canopy with spoiler, canopy moved } 22.9 \mathrm{~cm}\left(9^{\prime \prime}\right) \\
\text { forward of operator }\end{array}$ & 0.61 & 70.4 & 2.09 & 6 & 72.1 & 68.7 \\
\hline $\begin{array}{l}\text { Canopy with spoiler, canopy moved } 22.9 \mathrm{~cm}\left(9^{\prime \prime}\right) \\
\text { forward of operator }\end{array}$ & 2.03 & 65.9 & 0.42 & 6 & 66.3 & 65.6 \\
\hline $\begin{array}{l}\text { Canopy with spoiler, canopy moved } 22.9 \mathrm{~cm}\left(9^{\prime \prime}\right) \\
\text { forward of operator }\end{array}$ & 4.32 & 51.3 & 6.78 & 3 & 59.0 & 43.6 \\
\hline
\end{tabular}

CI confidence interval

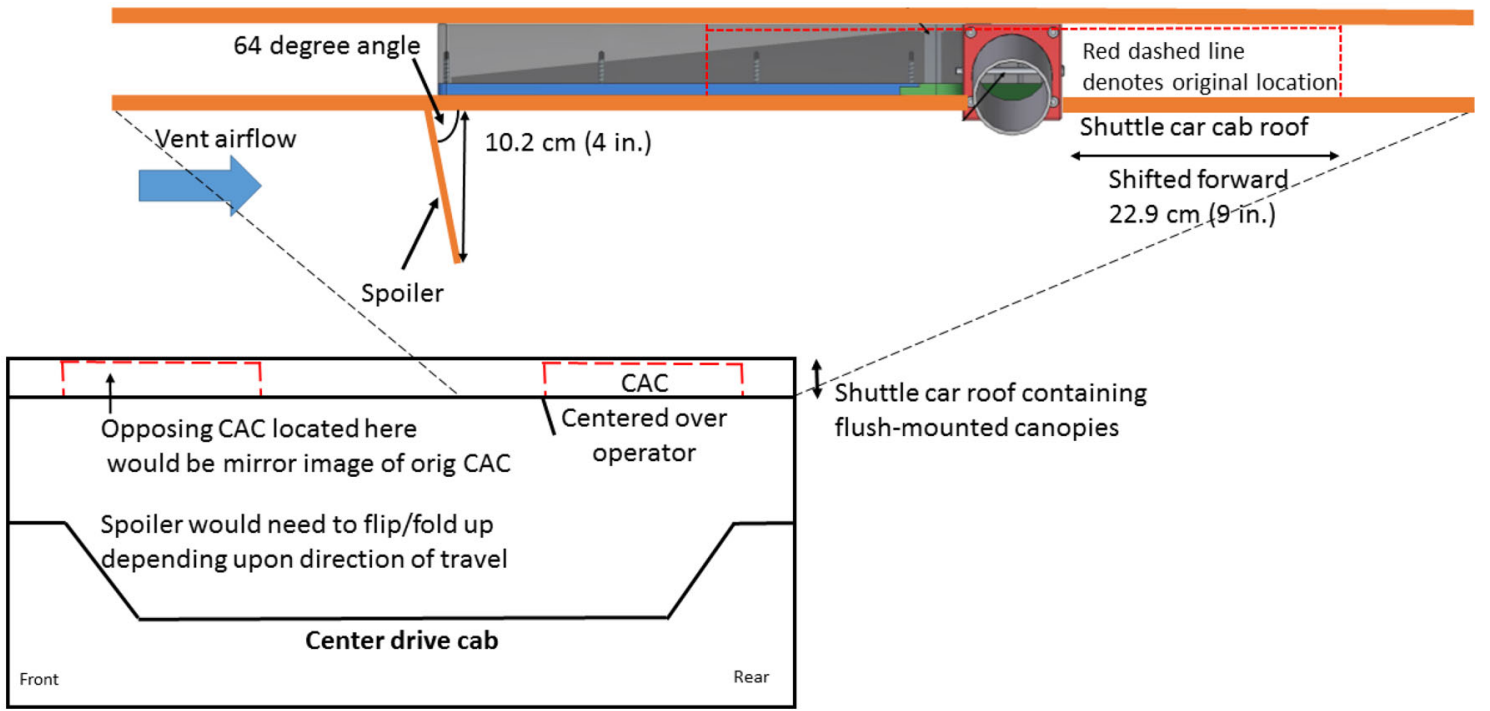

Fig. 11 Canopy air curtain built into cab roof, displaying forward shift of canopy location ( 9 in. forward) and spoiler to redirect ventilation airflow 
Table 5 Dust control reduction and associated statistics for center-drive shuttle car for an improved canopy configuration shown in Fig. 11

\begin{tabular}{|c|c|c|c|c|c|c|}
\hline Description & $\begin{array}{l}\text { Vent } \\
\text { airflow (m/ } \\
\mathrm{s})\end{array}$ & $\begin{array}{l}\text { Average } \\
\text { reduction }(\%)\end{array}$ & $\begin{array}{l}\text { Standard } \\
\text { deviation }\end{array}$ & Count & $\begin{array}{l}\text { Upper CI } \\
(95 \%)\end{array}$ & $\begin{array}{l}\text { Lower CI } \\
(95 \%)\end{array}$ \\
\hline $\begin{array}{l}\text { Two canopies, } 22.9 \mathrm{~cm}\left(9^{\prime \prime}\right) \text { forward, mounted underneath roof } \\
\text { with spoilers on both }\end{array}$ & 4.32 & 26.6 & NA & 1 & NA & NA \\
\hline $\begin{array}{l}\text { Two canopies, } 22.9 \mathrm{~cm}\left(9^{\prime \prime}\right) \text { forward, mounted underneath roof } \\
\text { with spoiler on operator position }\end{array}$ & 4.32 & 35.4 & NA & 1 & NA & NA \\
\hline $\begin{array}{l}\text { Two canopies, } 22.9 \mathrm{~cm}\left(9^{\prime \prime}\right) \text { forward, flush-mounted underneath } \\
\text { roof with spoiler on operator position }\end{array}$ & 4.32 & 54.8 & 1.26 & 3 & 56.2 & 53.4 \\
\hline
\end{tabular}

CI confidence interval

\subsection{Conclusions}

Laboratory tests conducted with the canopy air curtain as currently designed, and with its planned location on the shuttle car cab, has shown to be more than sufficient for dust reductions in airflow velocities up to $0.61 \mathrm{~m} / \mathrm{s}(120$ fpm), with reductions of $74 \%$ (center drive) and $83 \%$ (end drive). However, at $4.3 \mathrm{~m} / \mathrm{s}(850 \mathrm{fpm})$ ventilation airflow, the reductions were very low at $16 \%$ (center drive) and $6 \%$ (end drive) and not sufficient to meet the contract requirements of $60 \%$ dust reduction during the entire operation of the shuttle car.

To improve dust reductions from the CAC, modifications to the canopy locations were tested. Installing a spoiler and moving the CAC $22.86 \mathrm{~cm}$ (9 in.) forward from the operator location seem to provide the best improvement in the performance of the CAC. Dust reductions of $70 \%$ at $0.61 \mathrm{~m} / \mathrm{s}(120 \mathrm{fpm}), 66 \%$ at $2.0 \mathrm{~m} / \mathrm{s}(400 \mathrm{fpm})$, and $51 \%$ at $4.2 \mathrm{~m} / \mathrm{s}(850 \mathrm{fpm})$ ventilation airflows were achieved. Although the $60 \%$ dust reduction threshold was not met at $4.2 \mathrm{~m} / \mathrm{s}(850 \mathrm{fpm})$, a $51 \%$ reduction is close and is sufficient to proceed with field testing. In addition, the $4.2 \mathrm{~m} / \mathrm{s}$ (850 fpm) air ventilation quantity threshold was originally based upon a mine ventilation velocity measured in an intake entry and the maximum shuttle car speed of $9.6 \mathrm{~km} /$ hr (6 mph) (Joy Global 2016). Recent studies completed by NIOSH show that the maximum air ventilation quantity threshold may not be equal to mine intake air plus the maximum shuttle car speed (Shahan and Reed 2018), and relative velocity may be significantly lower than $850 \mathrm{fpm}$ in mines. In addition, the higher airflow a shuttle car encounters is generally associated with lower dust concentrations. In fact, the shuttle car operators' highest respirable dust exposure occurred when being loaded by the continuous miner in blowing face ventilation. Therefore, the modification of moving the CAC $22.9 \mathrm{~cm}$ (9 in.) forward and flush mounted onto the shuttle car cab roof should be sufficient to achieve the targeted $60 \%$ reduction.

These laboratory tests showed that the canopy air curtain for the shuttle car is successful at reducing respirable coal mine dust exposure at low ventilation velocities. Redesign of the CAC to shift it forward $22.9 \mathrm{~cm}$ (9 in.) with a spoiler and flush mount it onto the shuttle car roof should successfully protect the shuttle car operator from respirable coal mine dust as seen by the results from these tests. Other options to improve the dust control efficiency of the CAC could be evaluated, such as increasing the airflow to the $\mathrm{CAC}$ and/or enlarging the size of the CAC to have a single CAC over the entire canopy. But, these enhancements are probably not necessary for improving dust control efficiency. The laboratory testing on the shuttle car CAC demonstrates that it can successfully protect the shuttle car operator by reducing exposure to coal mine respirable dust. A field test is being planned to test the CAC at a mine site that uses blowing face ventilation.

Open Access This article is distributed under the terms of the Creative Commons Attribution 4.0 International License (http://crea tivecommons.org/licenses/by/4.0/), which permits unrestricted use, distribution, and reproduction in any medium, provided you give appropriate credit to the original author(s) and the source, provide a link to the Creative Commons license, and indicate if changes were made.

\section{References}

Colinet JF, Reed WR, Potts JD (2013) Impact on respirable dust levels when operating a flooded-bed scrubber in 20-foot cuts. U.S. Department of Health and Human Services, Centers for Disease Control and Prevention, National Institute for Occupational Safety and Health, DHHS (NIOSH) Publication 2014-105, RI 9693, Pittsburgh, PA

Engel M, Johnson D, Raether T (1987) "Improved canopy air curtain systems”. USBM Open File Report 25-88. US Bureau of Mines, Washington

Goodman JVR, Organiscak JA (2002) Evaluation of methods for controlling silica dust exposures of roof bolters. Trans Soc Min Metall Explor 312:133-137

Joy Global (2016) Haulage systems product overview. Komatsu America Corp, Rolling Meadows

Krisko WJ (1975) "Develop and test canopy air curtain devices". USBM Contract Report HO232067. US Dept. of the Interior, Bureau of Mines/Donaldson Company, Inc., Pittsburgh

Listak JM, Beck TW (2012) Development of a canopy air curtain to reduce roof bolters' dust exposure. Min Eng 64(7):72-79 
Natrella MG (1963) Experimental statistics. National Bureau of Standards Handbook 91. U.S. Department of Commerce, National Bureau of Standards, Washington

Potts JD, Reed WR, Colinet JF (2011) Evaluation of face dust concentrations at mines using deep-cutting practices. NIOSH Report of Investigations 9680. U.S. Dept. of Health and Human Services, Centers for Disease Control and Prevention, National Institute for Occupational Safety and Health, Office of Mine Safety and Health Research, Pittsburgh, PA

Reed WR, Joy GJ, Kendall B, Bailey A, Zheng Y (2017) Development of a roof bolter canopy air curtain for respirable dust control. Min Eng 69(1):33-39
Salem A, Begley R, Ross G (2016) "Progress Report \#2". NIOSH Contract \#:200-2015-63485. Marshall University Research Corp, Huntington

Shahan M, Reed WR (2018) Field investigation to measure shuttle car airflow velocities at a central Appalachian underground coal mine. 2019 SME Annual Meeting and Exhibit, Feb. 25-28, 2018, Minneapolis, MN. Pre-print 18-032 